\title{
A COMPARETIVE ANALYSIS OF AERODYNAMIC CHARECTERISTICS OF A VERTICAL AXIS VANE TYPE WIND TURBINE OVER EVEN AND ODD NUMBER OF BLADES
}

\author{
Zulfa ferdous $^{*, 1}$, Md. Quamrul Islam ${ }^{2}$ and M.Ali ${ }^{2}$ \\ ${ }^{1}$ SoutheastUniversity, Banani, Dhaka-1213, Bangladesh \\ ${ }^{2}$ Department of Mechanical Engineering, Bangladesh University of Engineering and \\ Technology (BUET), Dhaka-1000, Bangladesh
}

\begin{abstract}
This paper reports on the experimental investigation of the aerodynamic effects on even and odd number bladed vertical axis vane type rotor. The experiment was conducted with the help of a subsonic wind tunnel together with the experimental set-up of the vane type rotor and a spring balance. To ensure a Reynolds number independent approach, different stream flow was maintained. The flow velocities varied from $5 \mathrm{~m} / \mathrm{s}$ to $9 \mathrm{~m} / \mathrm{s}$ covering the Reynolds number from $0.6375 \times 10^{5}$ to $1.2 \times 10^{5}$. A four, five and six bladed vertical axis vane type rotor was used to determine the aerodynamic properties in dynamic condition. It is found that the power coefficient increases with increasing the number of blade but the significant effect of even and odd number blade is observed on the range of tip speed ratio. An odd number bladed rotor covered a wide range of tip speed ratio compare to the even number one.
\end{abstract}

Keywords: Aerodynamic characteristics, Power coefficient, Torque coefficient, Reynolds number, Tip speed ratio.

\section{INTRODUCTION}

The science of exploitation wind power is not a new concept but draws on the rediscovery of a long tradition, as the most conventional energy source like oil, coal, gas are not only non renewable but also causes serious threat to the environment; people are rethinking about the environment friendly renewable energy resources in large scale. Replacing the conventional fuels with renewable energy sources include wind energy, solar(photovoaltic) systems, solar thermal systems, biomass energy, geothermal energy, municipal waste etc. the costing of many of these technologies have come down considerably in recent years. Particularly wind energy, which is now competitive with conventional power sources in regions of strong winds, however, expected developments have not yet been achieved in wind driven machines. Arising from the increasing practical importance of wind turbine aerodynamics, there have been, over the past few decades, enormous increases in research works concerning laboratory simulations, full-scale measurements and more recently, numerical calculations and heoretical predictions of flows over a wide variety of vane type wind turbine. There are various types of wind turbines. The most common one is the horizontal axis wind turbine - the other one is the vertical axis wind turbine. The primary attraction of the vertical axis wind turbine is the simplicity of its manufacturing comparing to the horizontal axis one. The vertical axis vane type rotor is a drag based one. Drag based vertical axis wind turbines have relatively higher starting torque and less rotational speed than their lift based counterparts. Furthermore, their power output to weight ratio is also less. Because of the low speed, these are generally considered unsuitable for producing electricity, although it is possible by selecting proper gear trains. Drag based windmills are useful for other applications such as grinding grain, pumping water and a small output of electricity. A major advantage of drag based vertical axis wind turbines lies in their self-starting capacity, unlike the Darrieus lift-based vertical axis wind turbines. Among different vertical axis wind turbine, the vertical axis vane type wind turbine is a slow running wind machine with relatively lower efficiency. Still it is being used in the developing countries because of its simple design, easy and cheap technology for construction and good starting torque characteristics at low wind speed. It is independent of wind direction for power generation and also works even at low speed.

\section{AERODYNAMICS THEORY AND PERFORMANCE CHARECTERISTICS}

The aerodynamic analysis of vertical axis wind turbine is complicated due to the orientation in the oncoming wind as the rotational axis is perpendicular to the flow. This accounts a complicated aerodynamics compare to the conventional horizontal axis wind turbine. However, the configuration has an independence of wind direction. The main shortfalls are the high local angle of attack and the wake coming from the blades in the upwind part and axis. Understanding the aerodynamics of the pure drag type vertical axis wind turbine, will give important insight for improving the lift coefficient, and designing this turbine for better and more efficient harnessing of the wind energy.

\section{Lift Force}

The lift force, $\mathrm{L}$ is one of the major force components exerted on an airfoil section inserted in a moving fluid. 
It acts normal tyo the direction of fluid flow. This force is the consequence of uneven pressure distribution between the upper and lower blade surface and can be expressed as

$$
\mathrm{L}=0.5 \mathrm{C}_{1} \rho \mathrm{V}^{2} \mathrm{~A}
$$

where $\rho$ is the air density, $C_{1}$ is the lift coefficient and $A$ is the area of airfoil.

\section{Drag Force}

The drag force, D acts in the direction of fluid flow. Drag occurs due to the viscous friction forces and unequal pressure on the surfaces of the airfoil. Drag is a function of the relative wind velocity at the rotor surface, which is the difference between the wind speed and the speed of the surface, and can be expressed as

$$
\mathrm{D}=0.5 \mathrm{C}_{\mathrm{d}} \rho(\mathrm{U}-\Omega \mathrm{r})^{2} \mathrm{~A}
$$

where $\Omega r$ is the speed of the blade surface, $C_{d}$ is drag coefficient and $\mathrm{U}$ is the wind speed. The lift and drag coefficient values are usually obtained experimentally and correlated against the Reynolds number.

\section{Reynolds Number}

The Reynolds number, Re is the ratio of the inertia forces to the viscous forces. It is a non dimensional parameter that defines the charecteristics of the fluid flow conditions and mathematically given as

$$
\operatorname{Re}=\frac{\mathrm{UL}}{\nu}=\frac{\rho \mathrm{UL}}{\mu}=\frac{\rho \mathrm{V}_{\theta} \mathrm{c}}{\mu}
$$

where $\mu$ is the fluid viscosity, is the kinematic viscosity, $\mathrm{L}$ is the characteristics length scale, $\mathrm{c}$ is the blade chord length and $\mathrm{V}_{\theta}$ is the blade tip velocity.

\section{Tip Speed Ratio}

The tip speed ratio $\lambda$, is defined as the velocity at the tip of the blade, to the free stream velocity. It is given by

$$
\lambda=\frac{\mathrm{R} \omega}{\mathrm{V}}
$$

\section{Blade Solidity}

Solidity is defined as the percentage of the circumference of the containing material rather than air. High solidity machine generate much higher starting torque, though less efficient compare to a low solidity machine. Another advantage of high solidity wind turbine is that they do not need to be made with much precision as low solidity one, they are self starting one as well as provide $\mathrm{s}$ high torque even at low speed. Another advantage of high solidity wind turbine is that they do not need to be made with much precision as low solidity one, they are self starting one as well as provide $\mathrm{s}$ high torque even at low speed. The solidity may be defined as the ratio of blade area compared to swept area, mathematically, the blade solidity,

$$
\delta=\frac{\mathrm{Bc}}{2 \pi \mathrm{r}}
$$

where $\mathrm{B}$ is the number of blades. Changing the number of blades or the blade chord dimensions will alter the vertical axis wind turbine solidity. An increase in the chord results in a large aerodynamics force and consequently in high power.

\section{CONSTRUCTIONAL DETAIL}

The constructional detail of the Four, Five and Six bladed vane type rotor are shown in figure 3, 4 and 5 respectively. The rotor were made up of four, five and six half cylinders (blade) of diameter, $\mathrm{d}=65 \mathrm{~mm}$ and height, $\mathrm{H}=340 \mathrm{~mm}$ respectively. Rotor diameter, D was $200 \mathrm{~mm}$ to maintain $\mathrm{d} / \mathrm{D}$ ratio as $1 / 3$.

The cylinders were made of PVC material. Both the top and bottom ends of the rotor were fitted with end caps. The whole rotor was fixed on an iron frame by using a through shaft that was inserted into it and by two ball bearings. A pulley was attached at one end of shaft. A strip whose one side was tied to a spring balance and other side to a load carrying plate was prepared for passing over that pulley. A radium sticker was attached to that side of shaft. The spring balance was attached to the iron frame. The whole experimental set-up is shown in Figure 2.

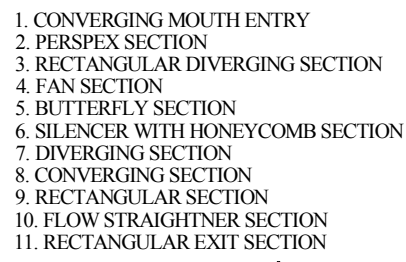

Figure1. Schematic diagram of the experimental set up.

\section{EXPERIMENTAL SETUP AND PROCEDURE}

The schematic diagram of the experimental set-up of the present investigation is shown in Fig. 1. An open circuit subsonic type wind tunnel was used to develop the required flow and the rotor was positioned at the exit section of the wind tunnel. The tunnel was $5.93 \mathrm{~m}$ long with a test section of $(490 \mathrm{~mm} \times 490 \mathrm{~mm})$ cross-section. The central longitudinal axis of the wind 
tunnel was maintained at a constant height from the floor. The converging mouth entry was incorporated into the system for easy entry of air into the tunnel and maintains uniform flow into the duct free from outside disturbances. The induced flow through the wind tunnel was produced by two-stage rotating axial flow fan of capacity $18.16 \mathrm{~m}^{3} / \mathrm{s}$ at a head of $152.4 \mathrm{~mm}$ of water and $1475 \mathrm{rpm}$ with each of the fans connected to a motor of $2.25 \mathrm{~kW}$ capacity and $2900 \mathrm{rpm}$. A butterfly valve, actuated by a screw thread mechanism was placed behind the fan and was used to control the flow. A silencer was fitted at the end of the flow controlling section in order to reduce the noise of the system. The diverging and converging section of the wind tunnel was $460 \mathrm{~mm}$ long and made of 16 SWG black sheets. The angle of divergence and convergence was $7^{\circ}$, which was done with a view to minimizing expansion and contraction loss and to reduce the possibility of flow separation. Other three outlet square $(610 \mathrm{~mm}$ each) sections were used to make the flow straight and uniform.

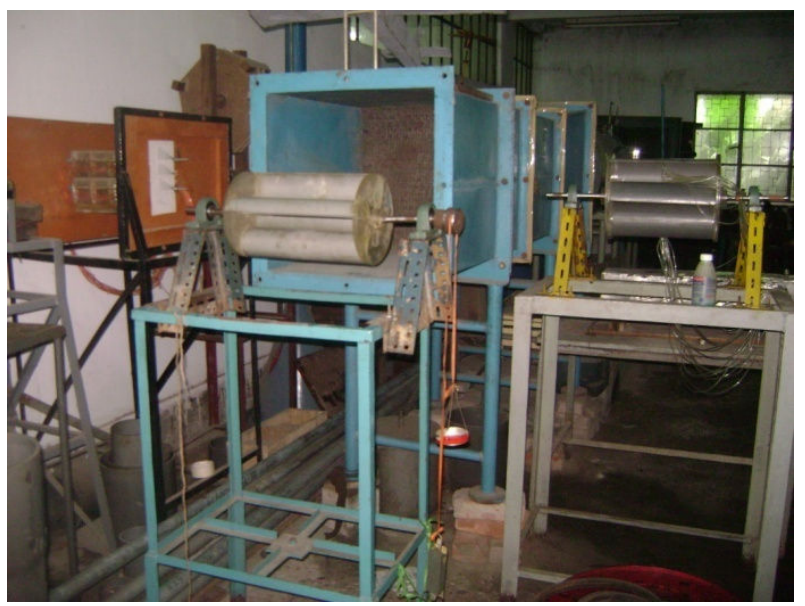

Figure 2. Pictorial diagram of the experimental set up.

At first, the velocity was measured without the model turbine at the sections which was placed in front of the rotor at different locations and average velocity was measured directly. The experimental set-up is shown in Figure 2. Non-contact electrical tachometer was used to measure the speed of the model wind turbine at different loading conditions. Wind speed behind the rotor was measured by a digital anemometer and the speed of the model wind turbine shaft having 4 , 5 and 6 bladed rotor at different Reynolds number were determined using a non-contact digital tachometer at different loading condition.

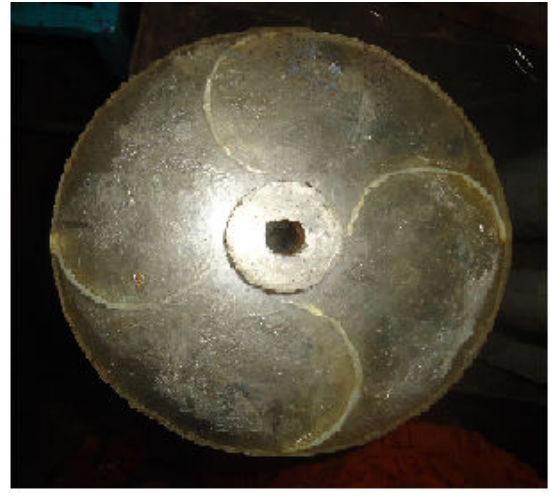

Figure 3. Four bladed rotor.

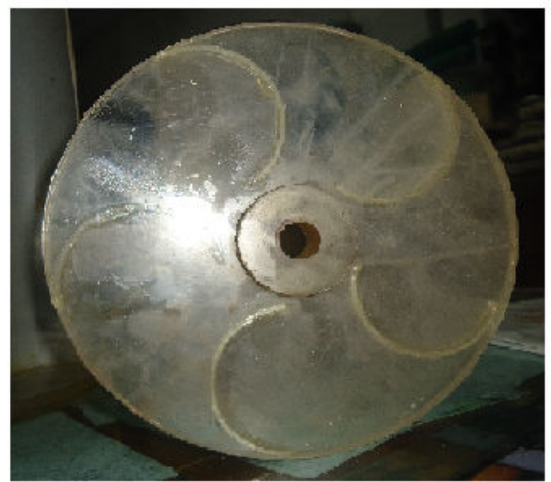

Figure 4. Five bladed rotor.

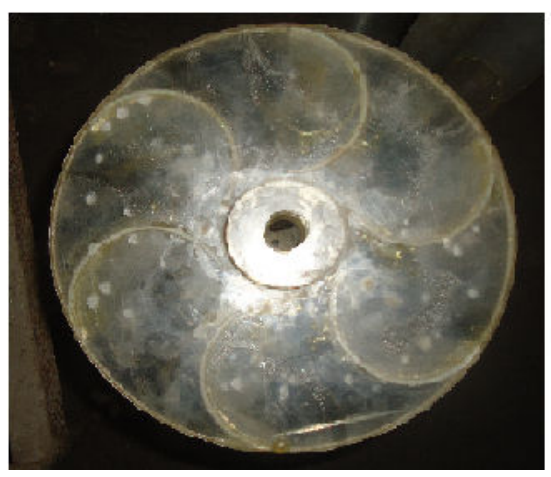

Figure 5. Six bladed rotor.

\section{RESULTS AND DISCUSSION}

A Reynolds number as well as blade number independent experiment has been performed by controlling the free stream velocities and by using four, five and six bladed rotor. The experimental results are presented in terms of power coefficient vs. tip speed ratio at different Reynolds number, in Figure 6 to Figure 10. From these figures it is observed that the power coefficient increases with increasing the tip speed ratio and after a certain point attaining the maximum value, the power coefficient decreases with increasing the tip speed ratio. It is also evident that the value of maximum power coefficient increases with 
increasing the number of blade. Another observation is that at each Reynolds number, the five bladed rotor covered a wide range of tip speed ratio compare to four and six bladed one.

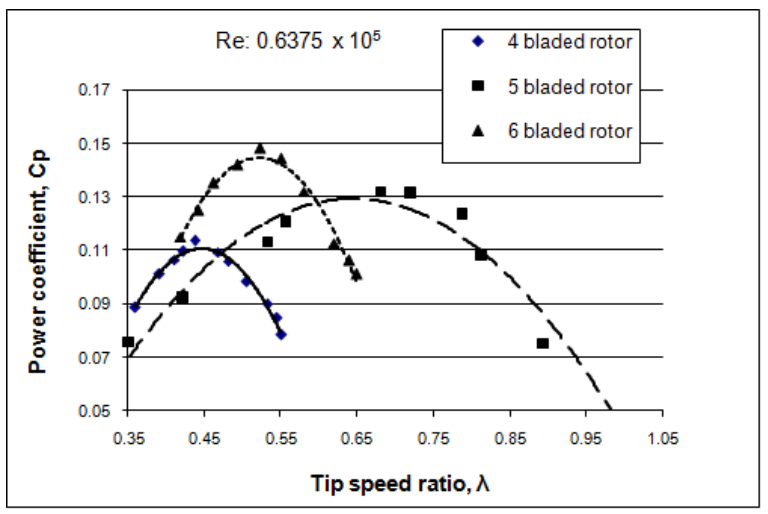

Figure 6. Power coefficient vs. tip speed ratio at Reynolds number $0.6375 \times 10^{5}$.

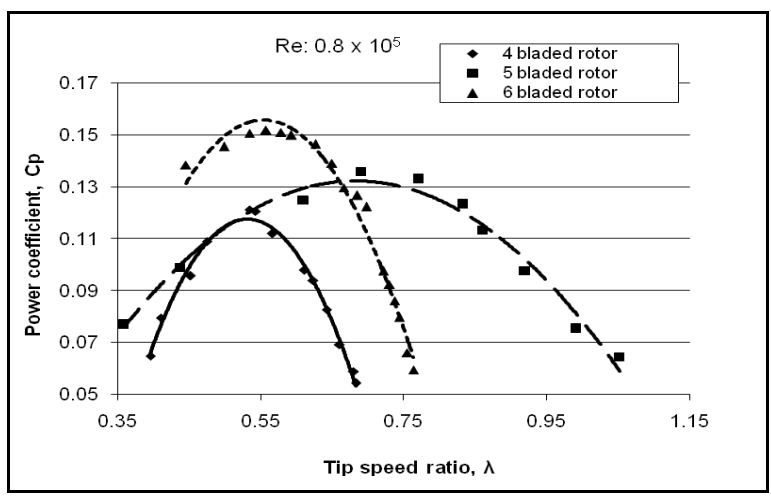

Figure 7. Power coefficient vs. tip speed ratio at Reynolds number $0.8 \times 10^{5}$.

Figure 4 depicts that the four bladed rotor covered around a range of $0.36-0.56$ tip speed ratio, where as the five and six bladed rotor covered around a range of 0.31-0.97 and 0.4-0.7 tip speed ratio respectively at Reynolds number $0.6375 \times 10^{5}$ This phenomenon is repeated for other Reynolds number as well. Figure 5 reveals that, the corresponding tip speed ratio covered by four, five and six bladed rotor are approximately $0.4-0.6,0.3-1$ and $0.45-0.8$ respectively at tip speed ratio $0.8 \times 10^{5}$. From Figure 6 these values are found as $0.4-0.7,0.35-1.1$ and $0.35-0.8$ respectively at tip speed ratio $0.9 \times 10^{5}$ In Figure 7 , these values are observed approximately as $0.48-0.9,0.38-1.1$ and $0.38-0.9$ respectively at Reynolds number $1.02 \times 10^{5}$. The last result also follow the same trend, the values observed approximately as $0.58-0.9,0.4-1.1$ and $0.38-0.8$ at Reynolds number $1.2 \times 10^{5}$. From the above data, it is clear that the rotor with an odd number blade (here five blade) covers a wide range of tip speed ratio compare to an even number one (here four and six blade) at any
Reynolds number of flow. While harnessing wind power this observation may play a good role to select the number of blade for a vertical axis wind turbine.

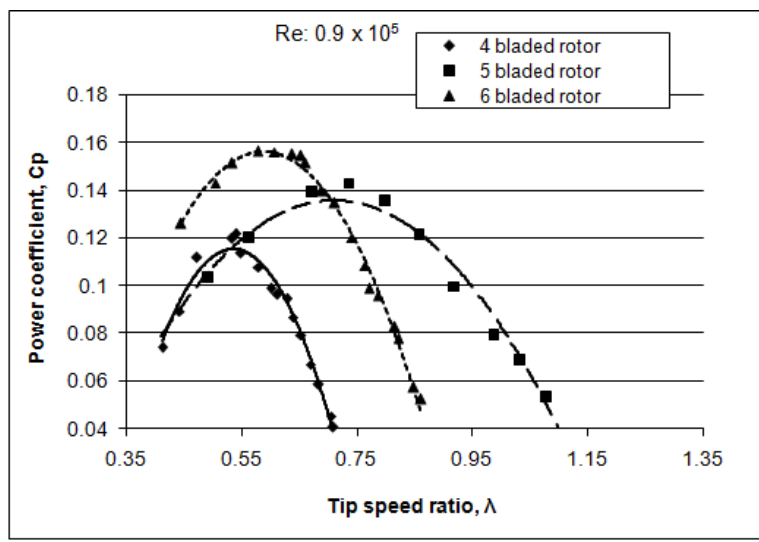

Figure 8. Power coefficient vs. tip speed ratio at Reynolds number $0.9 \times 10^{5}$.

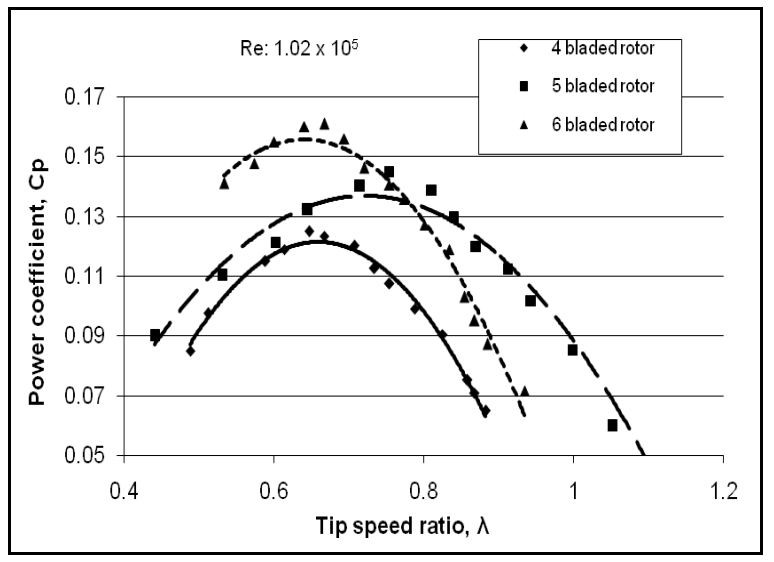

Figure 9. Power coefficient vs. tip speed ratio at Reynolds number $1.02 \times 10^{5}$.

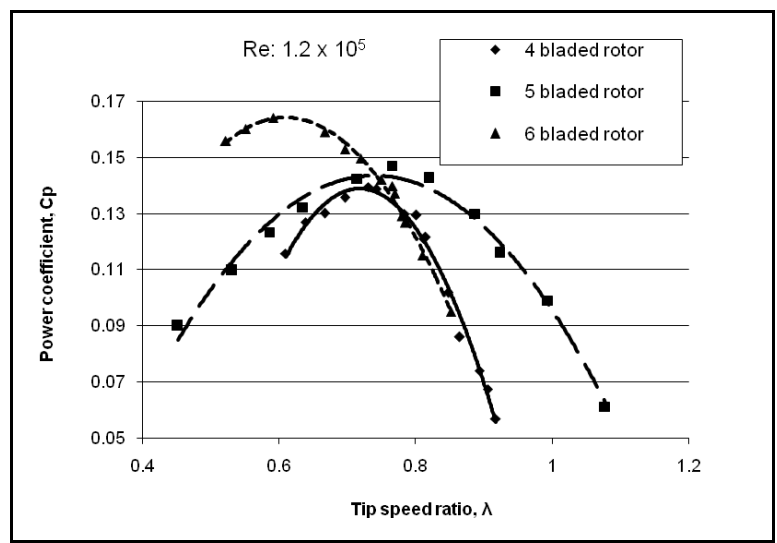

Figure 10. Power coefficient vs. tip speed ratio at Reynolds number $1.2 \times 10^{5}$. 


\section{CONCLUSION}

To obtain the aerodynamic characteristics in dynamic condition the rpm of the rotor at different loading conditions and the difference in tensions between two ends of the friction belt for different Reynolds number were measured. From these data, the changes in tip speed ratio, power coefficient, torque coefficient with the increase in load in the load carrying plate were determined at different Reynolds number. By varying the free stream velocity at different loading conditions, a Reynolds number independent approach was made. From the experimental analysis the following conclusion can be drawn:

1. The value of maximum power coefficient is higher for higher Reynolds number.

2. As the Reynolds number increases, the value of maximum power coefficient is shifted towards the higher tip speed ratio.

3. The value of maximum power coefficient increases with increasing the number of blades.

4. Odd number bladed rotor covered a wide range of tip speed ratio compare to an even number bladed rotor, where the number of blade does not play a significant role.

\section{REFERENCES}

1. Ahmmed, S., "Investigation and Analysis of Wind Pumping System for Irrigation in Bangladesh", Ph.D. Thesis, Bangladesh University of Engineering and Dhaka, Bangladesh, 2002.

2 Kamal, F. M. (2008), "Aerodynamic Characteristics of a Vertical Axis Vane Type Rotor", M.Sc. Engg. Thesis, Dept. of Mech. Engg., BUET.

3. Ogawa, T. and Yoshida, H. (1986), "The Effects of a Deflecting Plate and Rotor and Plates", Bull. JSME, vol. 29 , pp. $2115-2121$

4. Islam, A.K.M.S, Islam, M.Q., Mandal, A.C. and Razzaque, M.M. (1993), "Aerodynamic Characteristics of a Stationary Savonius rotor”, RERIC Int. Energy Journal, Vol. 15, No. 2. pp. 125-135.

5. Rahman,M. (2000), "Aerodynamic Characteristics of a Three Bladed Savonius Rotor",M.Sc. Engg. Thesis, Dept of Mech. Engg., BUET.

6.Bhuiyan, H. K. (2003), "Aerodynamic Characteristics of a Four Bladed Savonius Rotor", M.Sc. Engg. Thesis, Dept of Mech. Engg., BUET.

7. Huda, M.D., Selim, M.A., Islam, A.K., M., S. and Islam, M.Q. (1992), "The Performance of an S-shaped Savonius Rotor with a Deflecting Plate", RERIC Int. Energy Journal, Vol. 14, No. 1, Bangkok, Thailand.

\section{Nomenclature}

\begin{tabular}{lll}
\hline Symbol & Meaning & Unit \\
\hline $\mathrm{d}$ & Blade diameter & $\mathrm{mm}$ \\
$\mathrm{D}$ & Rotor diameter & $\mathrm{mm}$ \\
$\mathrm{H}$ & Rotor Height & $\mathrm{mm}$ \\
$\mathrm{Re}$ & Reynolds number & \\
$\mathrm{Cp}$ & Power coefficient & \\
$\mathrm{Cq}$ & Torque coefficient & \\
$\Lambda$ & Tip speed ratio & \\
\hline
\end{tabular}

